\title{
Preliminary Study on the State of Pre-Monsoon Time Climatic Comfort Over The Chitwan Valley, Nepal
}

\author{
Ram P. Regmi \\ National Atmospheric Resource and Environmental Research Laboratory (NARERL), Central Department of Physics, \\ Tribhuvan University, Kirtipur, Kathmandu, Nepal. \\ Correspondence: ram.p.regmi@gmail.com
}

\begin{abstract}
The preliminary assessment of pre-monsoon time climatic comfort over the Chitwan valley has been made with the application of Weather Research and Forecasting (WRF) Modeling System. Near surface temporal variation and spatial distribution of wind, temperature and humidity over the Chitwan Valley has been numerically simulated with the application of WRF Modeling System for the period of 12 to 19 May 2013. Calculation suggests that the valley captures a rather hot, humid and windy climate during the spring season. Large diurnal and spatial variation in temperature, humidity and wind prevails over the valley. The outskirts of the valley appears to be two to three degree warmer compared to the central area of the valley except for the afternoon time the reverse situation prevails. The outskirts of the valley are less humid compared to the central area of the valley except for the afternoon time. The difference in relative humidity in between outskirts and the central area can be as much as $30 \%$ during night and morning time whereas during the afternoon time the level of relative humidity over the outskirts areas can be 10 to $20 \%$ higher compared to central area of the valley. The western part of the valley floor is more humid than the eastern part. The Chitwan valley mostly remains windy except for morning hours. The valley floor remains rather windy most of the time except for southern and northwestern areas from Ratnanagar. In consideration with the predicted wind, temperature and humidity, it can be said that early monsoon time environment of the Chitwan valley is highly uncomfortable.
\end{abstract}

Keywords: Climatic comfort, climate change, atmospheric modeling, human health and Chitwan valley.

\section{INTRODUCTION}

The Chitwan valley is located in the southwestern plain of Central Nepal covering an area of 2218 $\mathrm{km}^{2}$ in proximity to the high mountainous range. The valley accommodates the seventh largest city of Nepal, the Bharatpur sub-metropolitan city, Ratnanagar municipality and several villages including the Chitwan National Park (CNP). The Bharatpur sub-metropolitan city along with the Ratnanagar municipality area are developing as regional industrial, commercial, education and health service centers.

The CNP is considered to be one of the most successful testimonies of nature conservation in the South Asia. Covering a pristine area of $932 \mathrm{~km}^{2}$ in the subtropical lowlands, the park aims to preserve a unique ecosystem with a large array of mammals, birds and vegetation species. The valley (see Figure 1 for locations and terrain structure) captures diverse topographic features consisting of Churia hills that gradually rising form 150 meters to over 800 meters, ox-bow lakes, alluvial rich flood plains and rugged low hills.

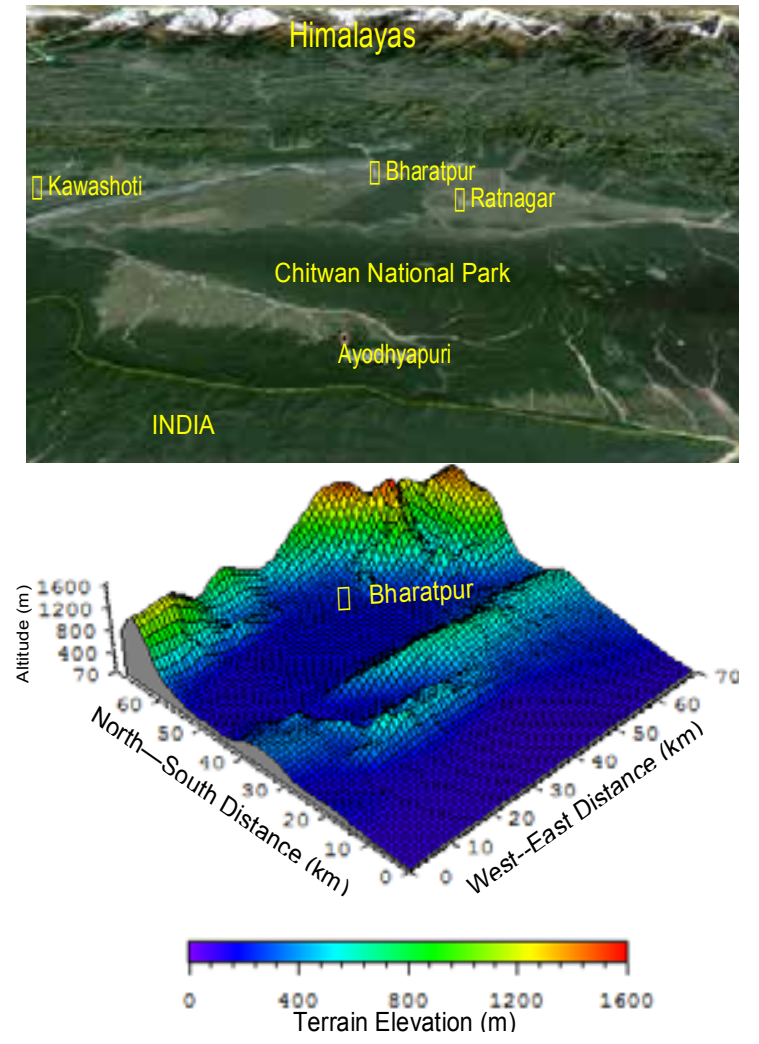

Figure 1: Google Earth view of Chitwan valley and its 
surroundings (upper) and Bird-Eye view of terrain structure of the study area (lower).

Valleys/basins create their own characteristic climate by containing and channeling meteorological fields. Prevailing climate can have profound influence on human and animal comfort and health. Assessment of the influence of atmospheric environment on human and animal comfort has become an area of great concern in the context of human health and disease, recreation, migration, tourism etc. Human are comfortable within a relatively small range of temperature and humidity conditions, roughly between 20 to $26.7^{\circ} \mathrm{C}$ and 20 to $80 \%$ relativity humidity.

When high temperatures are combined with low wind speeds and high humidity, the population may be put under severe thermal stress. The deterioration of human thermal comfort conditions in urban areas is a well-known and documented problem, potentially associated with the urban heat island effect (e.g. Giannaros et al., 2014). Accurate forecasting of thermal comfort conditions is thus critical for limiting the adverse impacts of heat waves and heat on human health. Research has shown that heat islands have considerable implications for air quality (Rosenfeld et al., 1998; Sarrat et al., 2006; Davies et al., 2007), human health (Conti et al., 2005 and Hanies et al., 2006) and regional/local atmospheric circulations (Miao et al., 2009).

Numerical modeling is considered to be an appropriate tool for studying the heat island effect, showing a wide area of successful applications. In particular, meso-scale atmospheric models such as WRF has been extensively used for investigating heat islands (Martilli et al., 2002; Kusaka and Kimura, 2004; Liu et al., 2006).

Under most environmental conditions, temperature represents a major portion of the driving force for heat exchange between environment and animal (Hahn, 1999). However, moisture and heat content of the air, thermal radiation, and airflow also affect the total heat exchange (Madar et al., 2006).
However, there have been no significant studies on characteristics of meteorological flow fields and climatic comfort over the valley. In this paper we present the diurnal variation and spatial distribution of near surface wind, temperature and humidity that largely determine the state of climatic comfort over the Chitwan valley during the pre-monsoon season.

\section{METHODOLOGY}

Prevailing meteorology over the Chitwan valley has been numerically simulated with the application of the state-of-the-art-of Weather Research and Forecasting (WRF) Modeling System (Skamarock et al, 2008). The model was initialized with NCEP 6-hourly meteorological data with a resolution of $1.0^{\circ} \times 1.0^{\circ}$ and the 24 categories of land use and 30 -second terrain elevation data by United States Geological Survey (USGS). A triply nested twoway interacting domain system has been utilized in which the coarse, fine and finest domain domain include $51 \times 51 \times 34$ grid points, and horizontal grid size is 9, 3 and $1 \mathrm{~km}$, respectively. A weeklong simulation was performed for the period of 12 to 19 May 2013. The centers of all the three domains are set at Ratnanagar $\left(27.6^{\circ} \mathrm{N}\right.$ and $\left.84.52^{\circ} \mathrm{E}\right)$.

The simulations were carried out using planetary boundary layer (PBL), and surface layer schemes and the NOAH land surface model (LSM), along the Dudhia short wave, RRTM long-wave parameterizations. The parameterization of scheme Lin et al. and the Kain-Fritsch convective parameterization scheme were used for coarse domain whereas no such parameterization scheme is used for the fine and finest domains (see Skamarock et al, 2008 for details).

\section{RESULTS}

The spatial and temporal distribution of wind, temperature, and humidity are discussed as revealed by the numerical simulation with WRF. Although, a weeklong simulation was carried out to assess the general characteristics of meteorological fields and diurnal periodicity, we will describe the temporal variation and spatial distribution of potential 
climatic parameters such as wind, temperature and relative humidity over the Chitwan valley for the period of 0600 LST 14 to 0600 LST 15 May 2013 as representative day for pre-monsoon season.

\subsection{Near surface wind pattern}

Figure 2 shows the representative plots of near surface wind over the Chitwan valley as predicted by WRF modeling system. Examining the series of model output for near surface wind in every 15 minutes interval, it can be said that the central area of the Chitwan valley may remain calm during the morning time (see Figure 2a-b). During the period western part of the valley may develop a large clockwise circulation due to the northerly drainage flow at the mouth of the Narayani River and the southeasterly flow in the southwestern part of the valley. The drainage flow appears to be effective only in the northwestern part of the valley. Over the hilly area of the CNP (see Figure 1) the flow pattern shows northwesterly and southwesterly flow over the southern and northern slopes of the hill. The maximum wind speed may reaches up to $7.8 \mathrm{~ms}^{-}$ ${ }^{1}$, particularly, at the mouth of the Narayani River. Relatively strong drainage flows also appears in the northeastern low mountain passes as well.

As the time progresses, the strength of both the clockwise circulation and the drainage flows along the Narayani River gorges significantly decrease and the divergence flow develops from around the Ratnanagar area due to the subsidence close to the 0900 LST (see Figure 2b). The easterly divergence flow converges with the westerly flow in the western part of the valley. Likewise, the northerly and north-westerly flow converges with the westerly and southwesterly flow over the CNP hilly area making west-east convergence line along the hill ridges. Close to 1000 LST, the divergence over the Ratnanagar disappears and the westerly and the southwesterly winds begins to influence the valley floor forcing to develop southerly flow over the northern part of the valley whereas situations over the CNP hills and nearby areas more or less remains the same. Over the central areas of the valley floor, the westerly form a series of convergence line developed by localized northwesterly and southwesterly wind systems (see Figure 2c).

The flow over the valley essentially remains the same except the wind speed gradually increases that may reach up to $6.8 \mathrm{~ms}^{-1}$ in the afternoon (see Figure $2 \mathrm{~d})$ and multiple convergence lines are apparent over the CNP hill. During the late afternoon, the dominant wind system over the valley appears to be the westerly and southwesterly. The low height hill of CNP appears to be effectively modifying the flow over it (see Figure 2e). The downslope winds over the southern slope of northern mountain ranges fully develop by this time and comes down to converge with westerly wind over the northwest area from Ratnanagar and the rather strong southwesterly wind from the CNP hilly area make a northwestsoutheast convergence line.
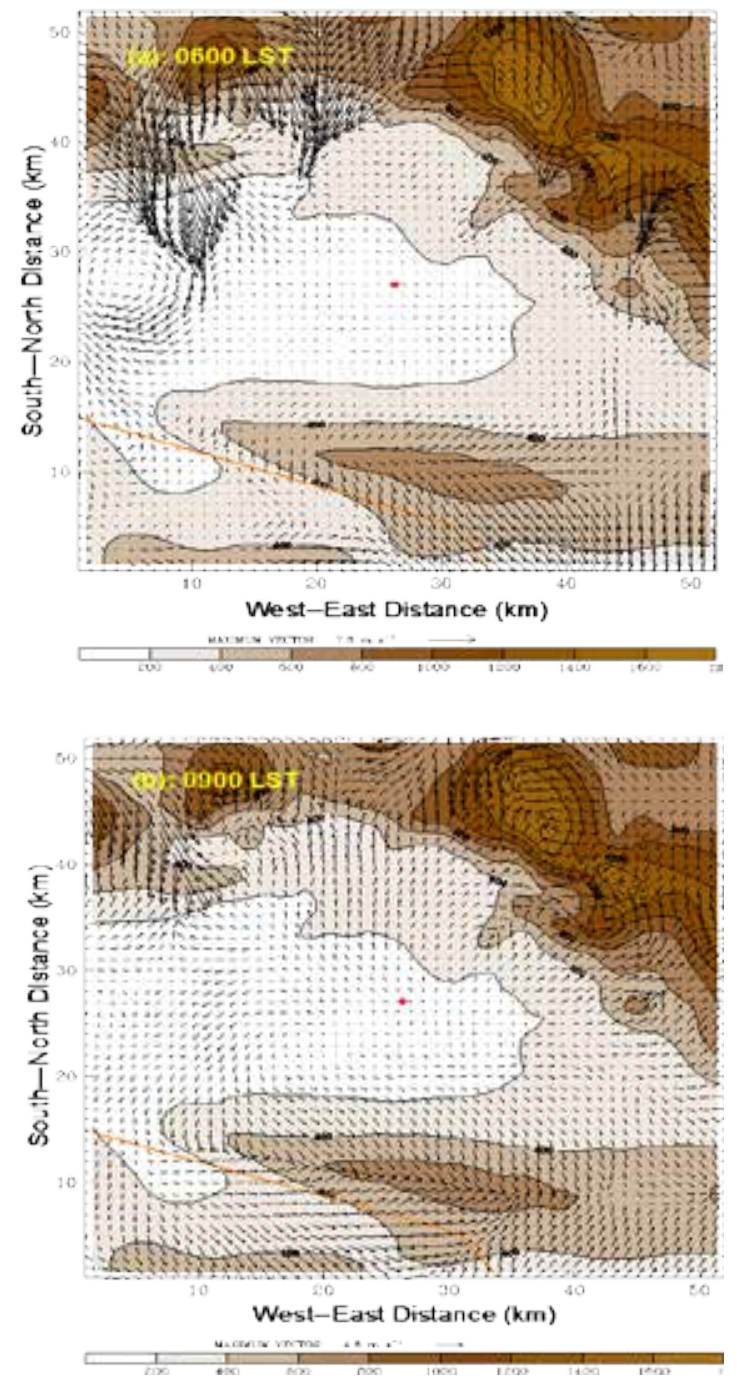


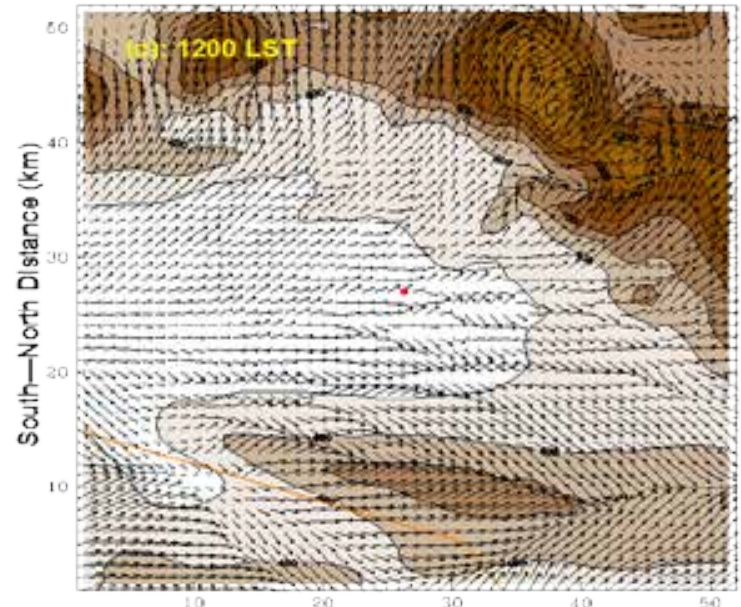

West-East Distance $(\mathrm{km})$
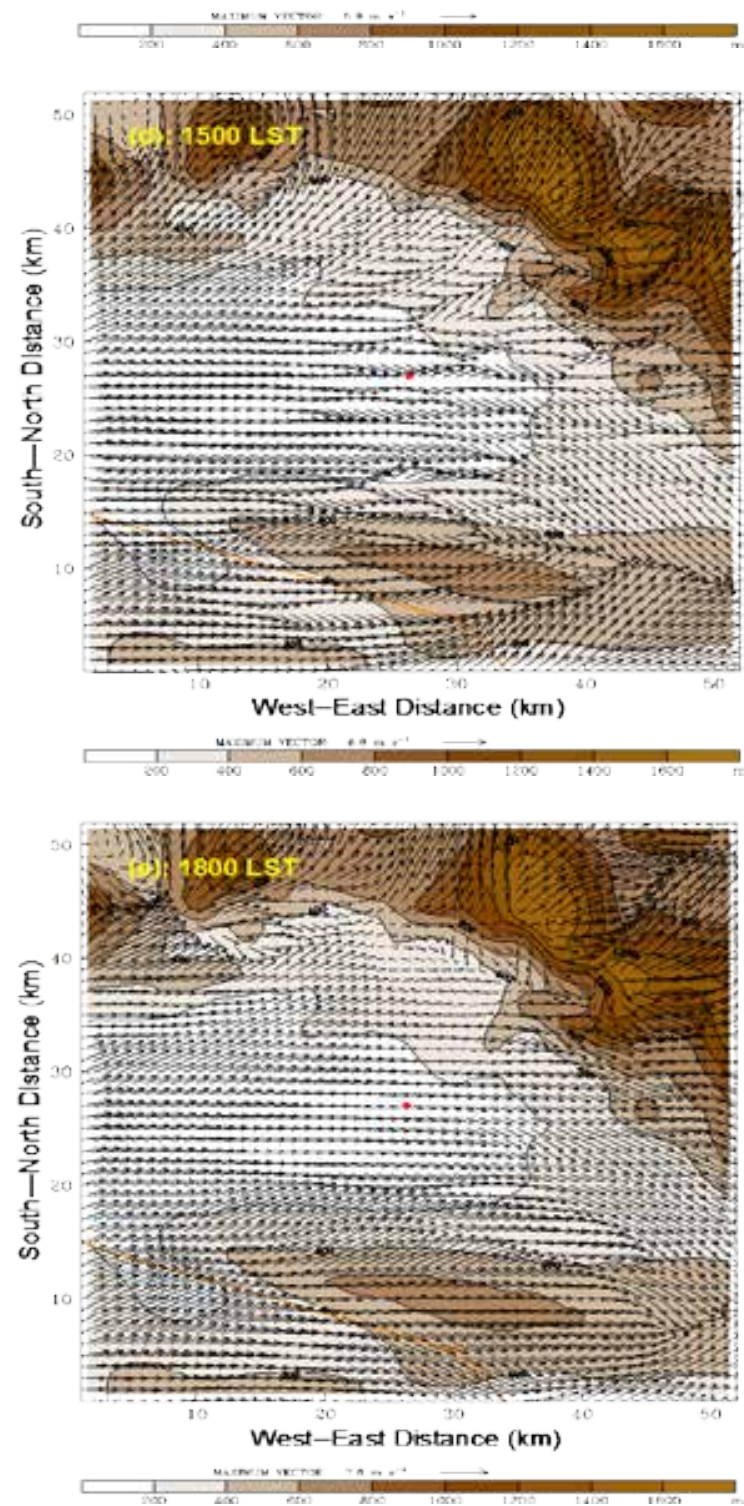
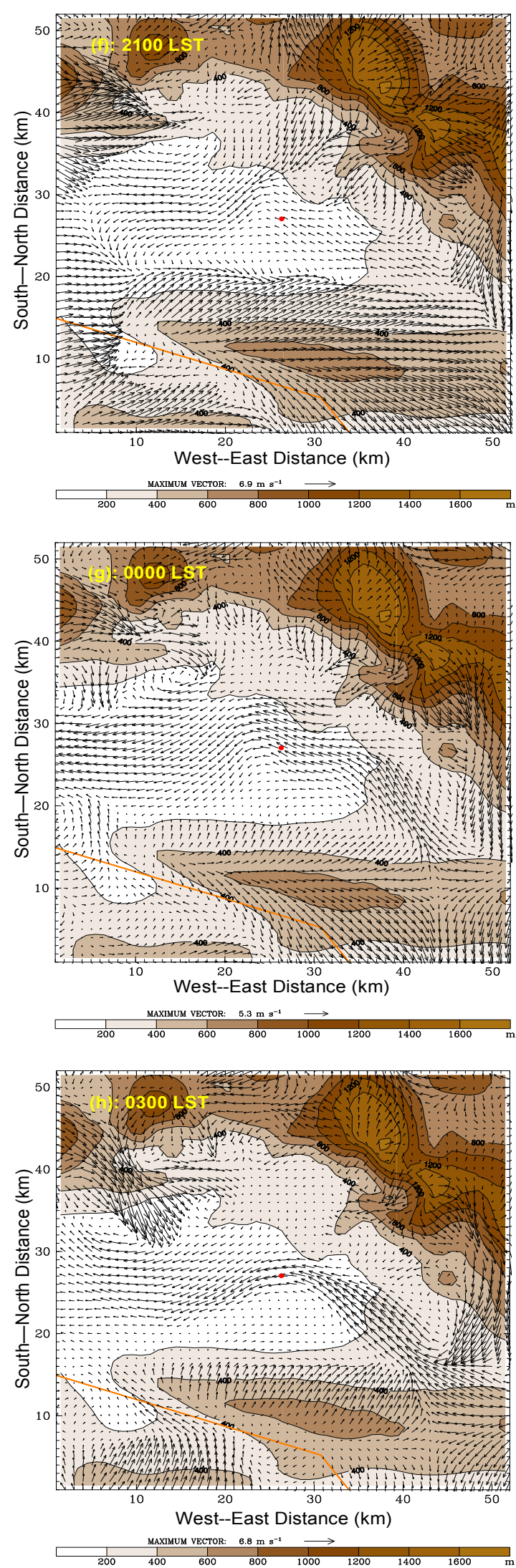

Figure 2: Spatial and temporal distribution of wind over the Chitwan valley. The location of Ratnanagar is indicated by filled circle at the center. 
Beyond this time, the westerly and southwesterly winds detached with downslope winds in the southern slope of the northern mountain ranges and by 2100 LST (see Figure 2f), the northeasterly downslope wind makes a wavy nature west to Ratnanagar and while converging with westerly it turns south and north. The wavy nature of the northeasterly downslope wind appears to be due to the penetration of easterly wind during the period. However, the nature of the wind over the CNP hilly areas largely remains the same except it appears to shrink from the north and the southwestern area of the hill become rather calm. Beyond this time, the northeasterly downslope wind weakens and the southeasterly wind strengthens. Very complex flow system prevails over the Chitwan valley such as formation of anticlockwise vortex over the areas just south of Ratnanagar, clockwise vortex in the southeast and in the northwest central area. The flow over the CNP hilly area still retains its basic characteristics pattern described earlier except the flow over the eastern part is rather northerly but the vortex pattern disappears when the midnight approaches.

During the midnight time (see Figure $2 \mathrm{~g}$ ), the westerly wind is replaced by the southwesterly penetrating from the southeast, which partially contributed by the northerly downslope wind in the eastern edge. The easterly wind turns towards the westerly over the area in between Ratnanagar and CNP hilly area becomes rather calm forming a feeble anticlockwise vortex. In the early morning (see Figure $2 \mathrm{~h}$ ), the southeasterly wind continues forming a clockwise vortex in the eastern edge of the calculation domain, anticlockwise vortex in the southern part of Ratnanagar and a strong clockwise vortex in the northwestern part of the valley. Moreover, the subsidence over the northeastern mountain area develops northeasterly wind in the areas north and northwestern to Ratnanagar. It is interesting to note that a highly localized diverging flow system of speed $6.6 \mathrm{~ms}^{-1}$ may prevails over the CNP hilly area and over the area beyond the boarder of Nepal (see Figure 0300 LST). Beyond this 0300 LST, the wind system over the Chitwan valley gradually returns into the situation similar to that described earlier for morning time. This may indicate that there is strong diurnal periodicity in the wind pattern over the Chitwan valley during the season.

\subsection{Surface temperature distribution}

Figure 3 shows the spatial and temporal distribution of surface level temperature over the Chitwan valley. Like in the case of near surface wind distribution discussed above, only a sample figures are shown although the temperature distribution was calculated for every 15 minutes interval. The distribution of temperature over the valley during the morning time (see Figure 3a) shows that the central part of the valley around the Ratnanagar area appears to be the lowest within the valley floor and is about $22^{\circ} \mathrm{C}$ whereas the large area of the lowland valley floor surrounding the Ratnanagar area holds the temperature of about $24^{\circ} \mathrm{C}$. The outskirts of the valley captures rather warm environment where the temperature may reach up to $29^{\circ} \mathrm{C}$, particularly, in the northern and northwestern outskirts. Over the CNP hilly area, it is about $26^{\circ} \mathrm{C}$. The minimum temperature of about $18^{\circ} \mathrm{C}$ appears over the northeastern mountaintops.

After sunrise, the temperature distribution over the valley floor quickly changes. Reaching the late morning (see Figure $3 b$ ), the valley the whole valley floor and lowland areas gains temperature of about $30^{\circ} \mathrm{C}$ except a small area in the central part of the valley where the temperature is about $28^{\circ} \mathrm{C}$. By 0900 LST, the temperature over the central area of the valley tends to equilibrate the temperature over the outskirts of the valley. The temperature over the northeastern mountainous area tends to be around $22^{\circ} \mathrm{C}$. However, the temperature over the CNP hilly area appears to be one to two degree less than over the valley area. Interestingly, small areas at eastern mouth of the valley and southwestern outskirt appear to possess relatively higher temperature than the central valley area. 
Close to the noontime (see Figure 3c), the whole valley area possesses the temperature of about 35 to $36^{\circ} \mathrm{C}$ whereas the outskirts of the valley and the CNP hilly areas possess 28 to $30^{\circ} \mathrm{C}$. The lowest temperature over the calculation domain appears to be about $22^{\circ} \mathrm{C}$ on the top of the northeastern mountains. The situation remains more or less the same until the late afternoon (see Figure 3d) with minor changes. However, beyond 1600 LST, significant decrease in temperature can be seen over the whole valley floor except the area around Ratnanagar and south to it where the temperature may remain as much as $35^{\circ} \mathrm{C}$ (see Figure $3 \mathrm{e}$ ). In the evening, the valley floor temperature becomes about $28^{\circ} \mathrm{C}$ (see Figure $3 \mathrm{f}$ ) whereas the temperature over the outskirts remains higher than $32^{\circ} \mathrm{C}$.
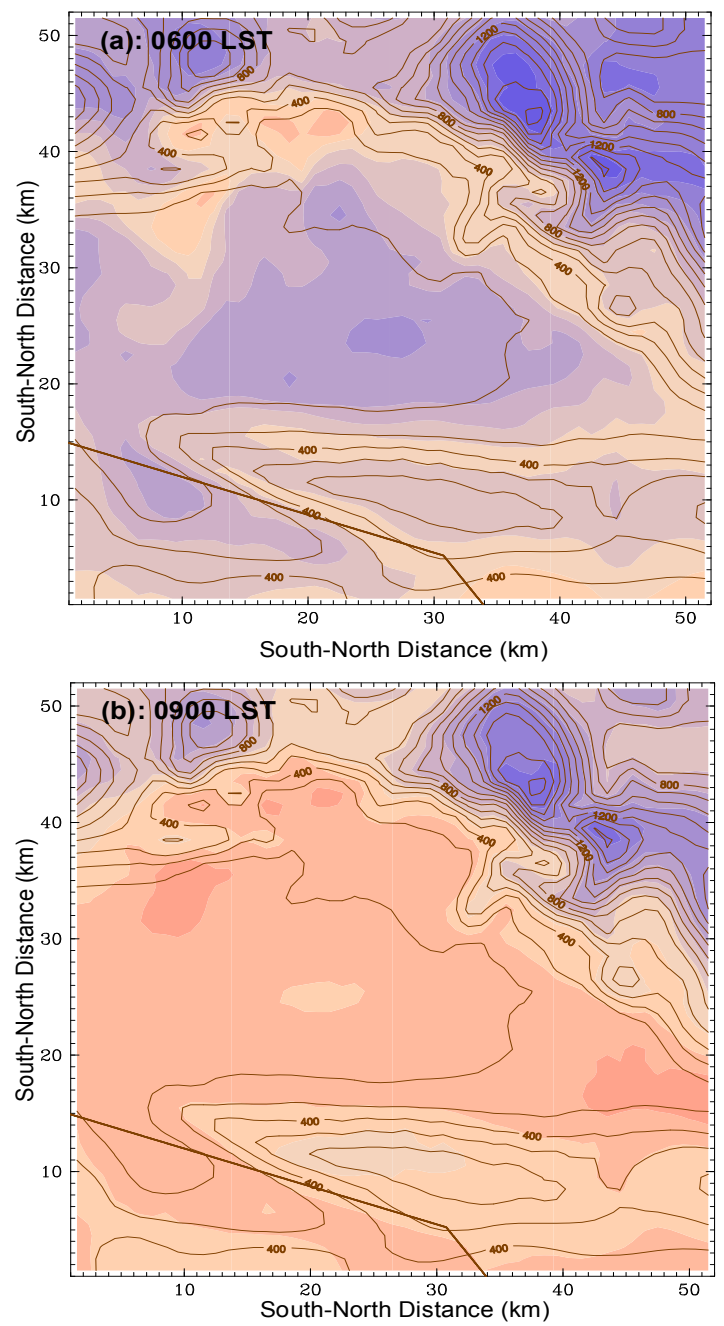
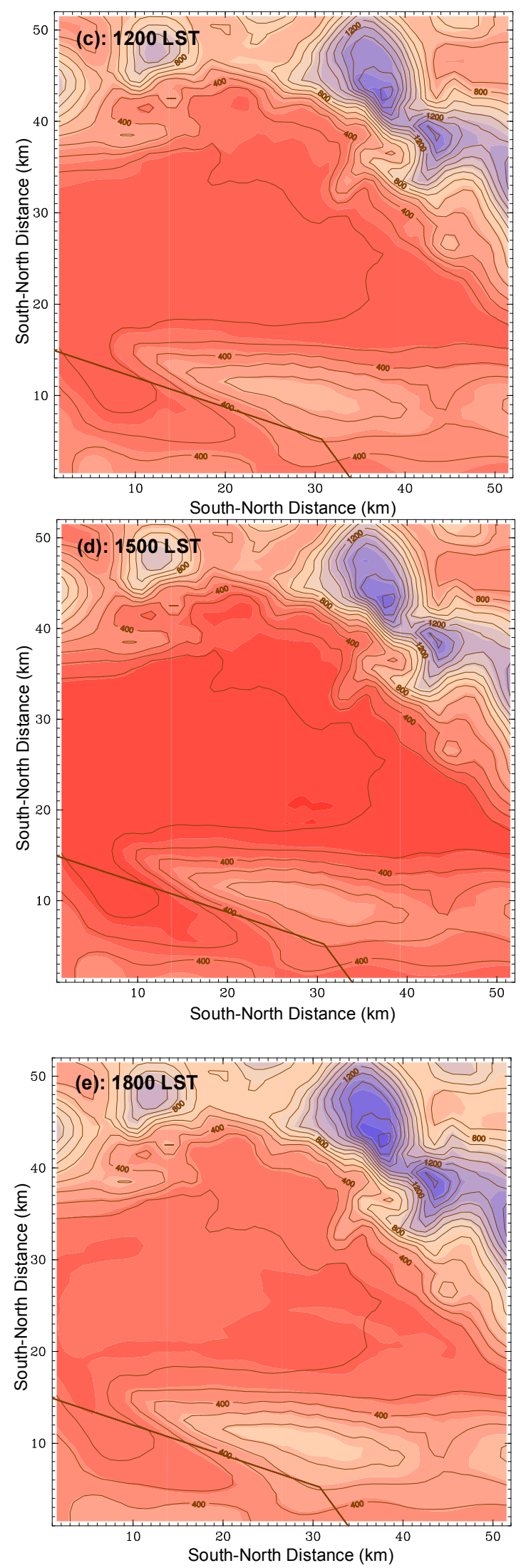

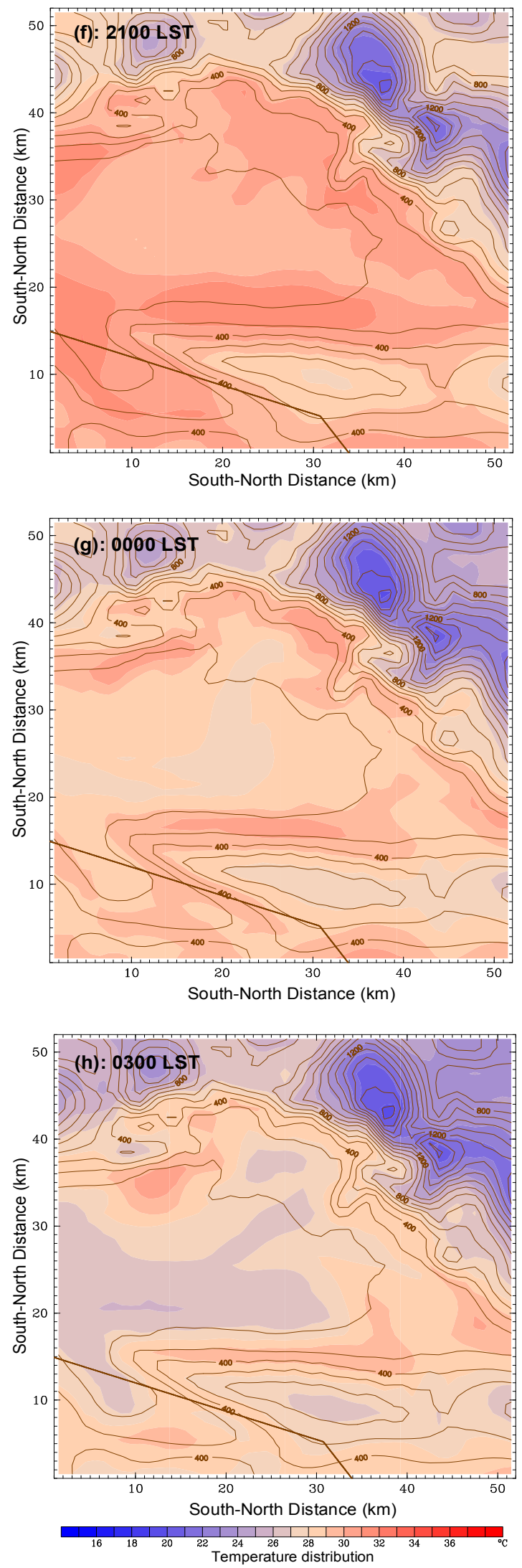

Figure 3: Spatial and temporal distribution of surface level temperature over the Chitwan valley.
The southern part of the valley close to the northern slope of CNP hilly area, the temperature appears to be more than $33^{\circ} \mathrm{C}$. Close to the midnight (see Figure $2 \mathrm{~g}$ ), the lowest central part of the valley and the CNP hilly area attends the temperature of about $26^{\circ} \mathrm{C}$ whereas the outskirts possesses the temperature more than $29^{\circ} \mathrm{C}$. Over the northeastern mountaintop area attains $17^{\circ} \mathrm{C}$.

In the early morning (see Figure $3 \mathrm{~h}$ ), western and southern valley area's temperature becomes close to $24^{\circ} \mathrm{C}$ whereas the over the outskirts of the valley it is around $28^{\circ} \mathrm{C}$. The distribution of the temperature over the Chitwan valley gradually returns to the same situation for morning time describe earlier.

Examining the series of spatial and temporal distribution for two days, it can be said that the Chitwan valley executes a diurnal periodicity for temperature during the season. One of the interesting aspects of temperature that the outskirts of the valley lose to the mountain possessed rather higher temperature compared to the central area of the valley.

\subsection{Surface humidity distribution}

Figure 4 show the sample plots of spatial distribution of relative humidity for every three hours over the Chitwan valley. Examining the distribution of humidity over the valley for every 15 minutes, it can be said that during the morning time just before the sunrise, the relative humidity over the central valley remains to be around $75 \%$ that gradually decreases to about $60 \%$ while reaching the outskirts of the valley. The outskirts of the valley, particularly, the northeastern part appears to possess rather low humidity and is about 40\% (see Figure 4a). Over the CNP hilly and northeastern mountainous areas it varies from 50 to $55 \%$.

After sunrise, the humidity over the outskirts of the valley and over the CNP hilly area noticeably increased whereas the level of humidity over the central valley area decreases. In the late morning the level of humidity over the valley as well as over the northern and northeastern outskirts appears to be 
$50 \%$ whereas over the central and limited area of $\mathrm{CNP}$ as well as over the northeastern mountainous area it is about $55 \%$. The minimum level of humidity appears over the eastern edge of the valley where it is less then $45 \%$ (see Figure $4 b$ ).

Close to the noontime (see Figure 4c), the humidity over the valley floor reduces to $40 \%$. The level of humidity during the period over the southern area of Ratnanagar appears to be around 35\%. Over the northeastern mountainous area it is about 60 to $65 \%$. Over the CNP hilly area and over the southeastern area it is about $50 \%$. In the afternoon (see Figure 4d), the valley floor except the CNP hilly area and in the northwest outskirts of the valley it is about $35 \%$. However, the northeastern outskirts, the humidity appears to be only about $25 \%$.
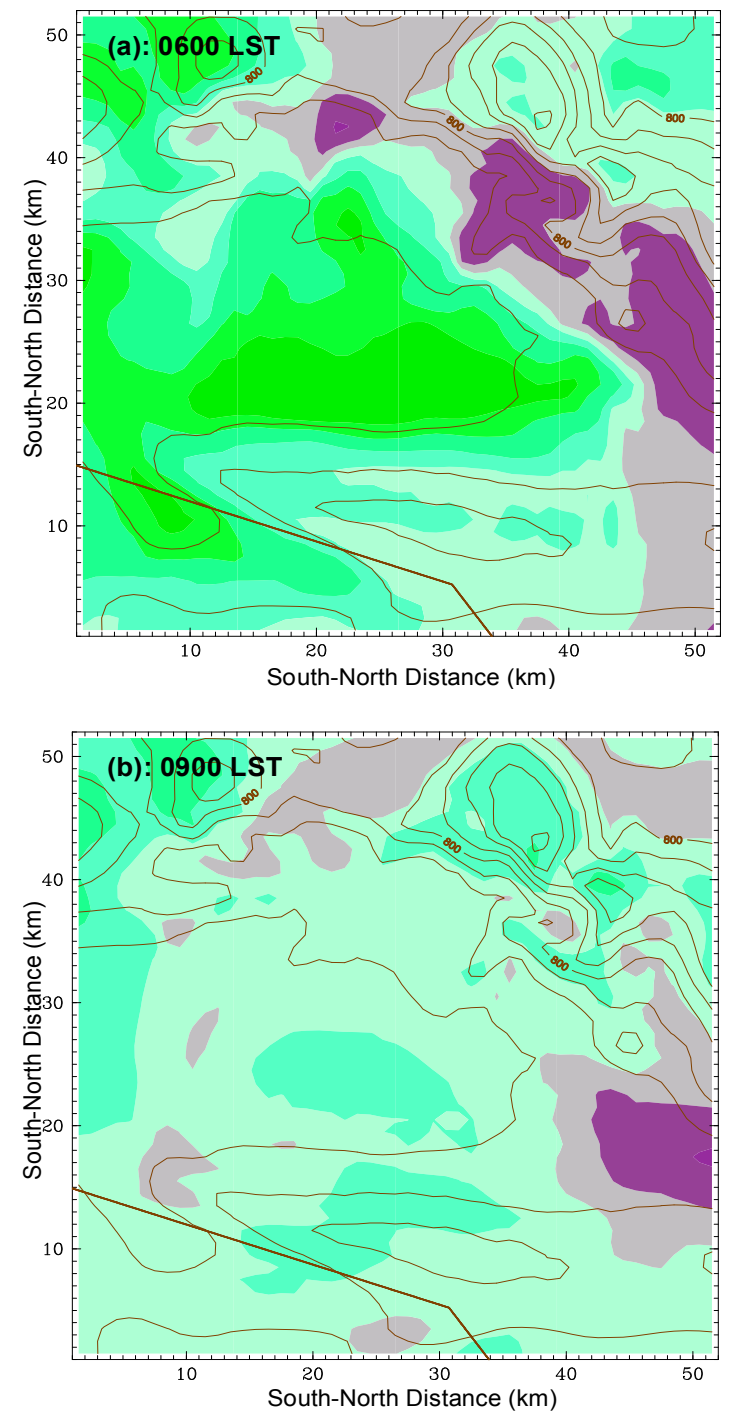
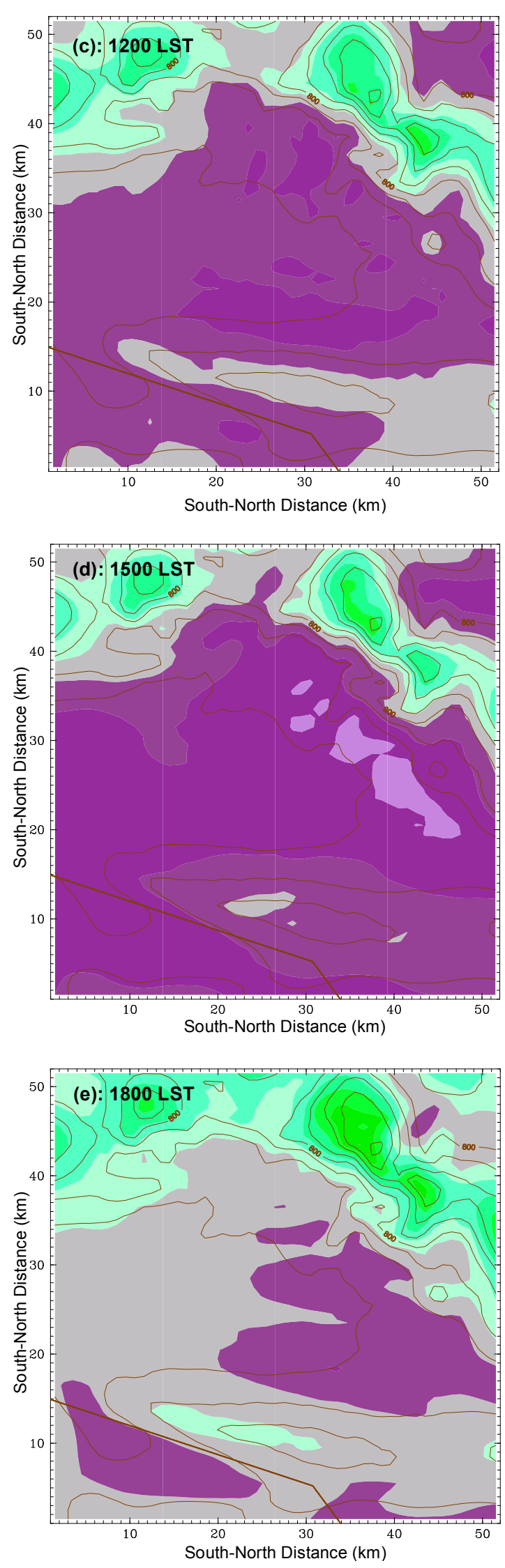

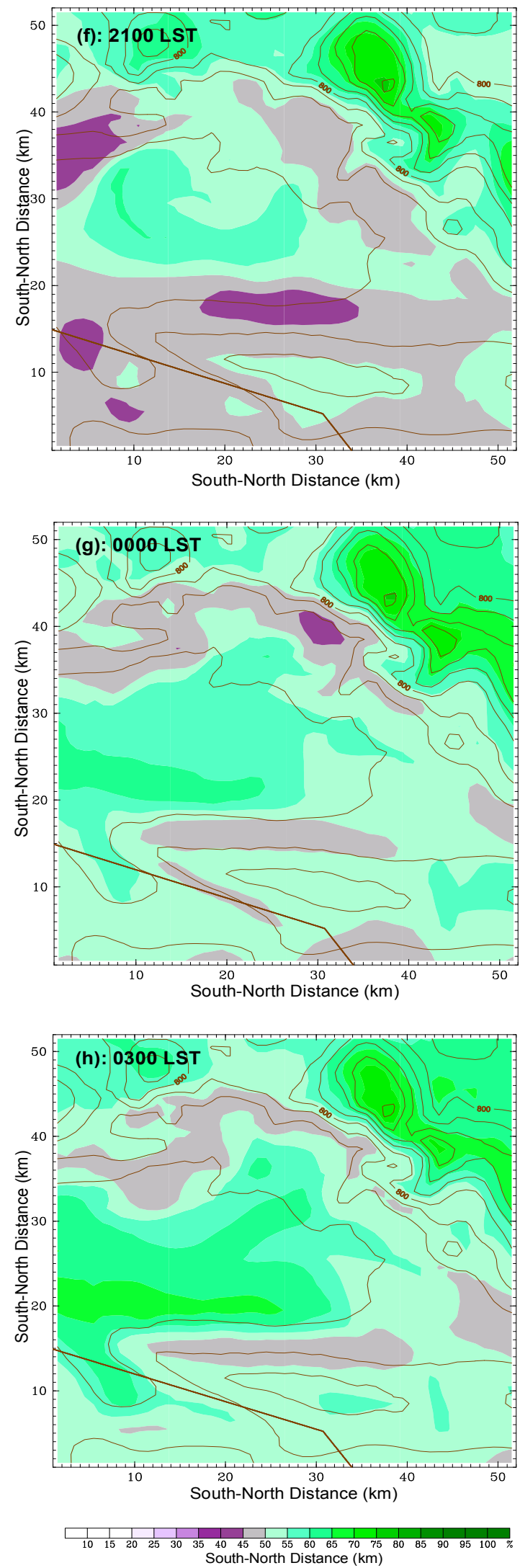

Figure 4: Spatial and temporal distribution of relative humidity over the Chitwan valley.
However, over the northwestern and northeastern mountainous areas it may vary from 50 to $60 \%$. During the late afternoon (see Figure 4e), the level of humidity tends to increase from west pushing the low humidity area towards the east. By this time, the level of humidity over the valley floor becomes more than $45 \%$ whereas over the central, particularly, the western part of the valley floor still possesses the relative humidity of bout $35 \%$. The hilltop area of CNP gains humidity to about $60 \%$ by this time. In the evening (see Figure 4f), the low land area of the valley quickly gains humidity and it may reach to about 60 to $65 \%$. The humidity over the northeastern mountain may reach more than $70 \%$ until the midnight (see Figure $4 \mathrm{~g}$ ).

In the early morning, a narrow strip of high humidity area extending from west and up to central area holds the humidity of about 70 to $75 \%$ and the area just north to this high humidity narrow strip, the humidity that ranges from 60 to $65 \%$ (see Figure 4h) whereas the northern slope of the CNP hill and the northeastern, northern and eastern outskirts of the valley it is only about $50 \%$ during the same period. As the morning progresses, the distribution of humidity over the valley floor gradually return to the same situation described earlier for morning time. Like the wind and temperature, the relative humidity distribution also shows diurnal periodicity over the Chitwan valley.

The simulated temporal and spatial distribution of relative humidity reveals that the outskirts of the valley generally captures as much as $20 \%$ less humidity compared to the central area of the valley except during the afternoon time. It can also be seen that there is inverse relationship in the distribution of relative humidity and temperature.

\section{CONCLUSION}

Climaticcomfortandadaptationis oneoftheimportant public issues that are yet to be address properly despite its high correlations with human and animal health and wellbeing. Present study has attempted to assess the spatial and temporal distribution of 
potential climatic parameters such as temperature, humidity and wind over the Chitwan valley with the application of Weather Research and Forecasting Modeling System during the pre-monsoon time. The study reveals that pre-monsoon time environment of the valley is highly uncomfortable and needs to be address to improved health and comfort for human and protected animals. A more detail and yearlong studies complemented with field observation is desired for better understanding of the issue and to develop necessary adaptation policies.

\section{ACKNOWLEDGEMENTS}

Present research is one of the by-products of Institutional Grants Research Project awarded by University Grants Commission, Nepal. The contributions in preparing images and comments of Ms. Sangeeta Maharjan, NARERL are acknowledged.

\section{REFERENCES}

1. A.Haines, R.S. Kovatsa, D. Campbell-Lendrumb and C. Corvalanb, 2006: Climate change and human health: Impacts, vulnerability and public health. Journal of the Institute of Public Health, 120, 585-596.

2. Conti, S., Meli, P., Mineli, G., Solimini, R., Toccaceli, V., Vichi, M., Beltrano, C., and Perini, L., 2005: Epidemiologic study of mortality during the summer 2003 heat wave in Italy, Environ. Res. 98, 390-399.

3. Davies, F., Middleton, D. R., and Bozier, K. E., 2007: Urban air pollution and measurements of boundary layer height, Atmos. Environ., 41, 4040-4049.

4. Giannaros T. M., D. Melas, I. A. Daglis and I. Keramitsoglou, 2014: Development of an operational modeling system for urban heat islands: An application to Athens, Greece. Nat. Hazards Earth Syst. Sci, 14, 347-358.

5. Hahn G. L., 1999: Dynamic response of cattle to thermal heat loads. J. Anim. Sci., 77 (suppl. 2), 10-20.
6. Kusaka, H. and Kimura, F., 2004: Coupling a single-layer urban canopy model with a simple atmospheric model: impact on urban heat island simulation for an idealized case, J. Meteorol. Soc. Japan, 82, 67-80.

7. Liu, Y., Chen, F., Warner, T., and Bassara, J., 2006: Verification of a mesoscale dataassimilation and forecasting system for the Oklahoma City area during the Joint Urban 2003 field project, J. Appl. Meteorol. Climatol., 45, 912-929.

8. Madar T. L., M. S. Davis and T. Brown-Brandl, 2006: Environmental factors influencing heat stress in feedlot cattle. J. Anim. Sci., 84: 712719.

9. Martilli, A., Clappier, A., and Rotach, M. W., 2002: An urban surface ex- change parameterization for mesoscale models, Boundary-layer Meteorol., 104, 261-304.

10. Miao, S., Chen, F., Lemone, M. A., Tewari, M., Li, Q., and Wang, Y., 2009: An observational and modeling study of the characteristics of urban heat island and boundary layer structures in Beijing, J. Appl. Meteorol. Climatol., 48, 484-501.

11. Rosenfeld, A. H., Akbari, H., Romn, J. J., and Pomerantz, M., 1998: Cool communities: strategies for heat island mitigation and smog re- duction, Energ. Buildings, 28, 51-62.

12. Sarrat, C., Lemonsu, A., Masson, V., and Guedalia, D., 2006: Impact of urban heat island on regional atmospheric pollution, Atmos. Environ., 40, 1743-1758.

13. Skamarock, W. C., Klemp, J. B., Dudhia, J., Gill, D. O., Barker, D. M., Duda, M. G., Huang, X. Y., Wang, W., and Powers, J. G., 2008: A description of the advanced research WRF version 3, NCAR Technical Note (NCAR/TN475+STR), Boulder, Col- orado, USA. 